\title{
Article \\ Changes in Microstructure, Germination, Sprout Growth, Phytochemical and Microbial Quality of Ultrasonication Treated Adzuki Bean Seeds
}

\author{
Kai-Ying Chiu
}

Citation: Chiu, K.-Y. Changes in

Microstructure, Germination, Sprout Growth, Phytochemical and Microbial Quality of Ultrasonication Treated Adzuki Bean Seeds.

Agronomy 2021, 11, 1093. https:// doi.org/10.3390/agronomy11061093

Academic Editor: Giuseppe Colla

Received: 22 April 2021

Accepted: 26 May 2021

Published: 28 May 2021

Publisher's Note: MDPI stays neutral with regard to jurisdictional claims in published maps and institutional affiliations.

Copyright: (C) 2021 by the author. Licensee MDPI, Basel, Switzerland. This article is an open access article distributed under the terms and conditions of the Creative Commons Attribution (CC BY) license (https:// creativecommons.org/licenses/by/ $4.0 /)$.
Department of Post-Modern Agriculture, Mingdao University, Peetow, Changhwa County 523, Taiwan; cky@mdu.edu.tw; Tel.: +886-0953-835-832

\begin{abstract}
Sprout is a nutritious ready-to-eat vegetable. In this study, we examined the effects of ultrasonication treatments (treated with 28,40 or $80 \mathrm{kHz}$ frequency for $10 \mathrm{~min}$ at $25^{\circ} \mathrm{C}$ ) on the changes in microstructure, seed hydration and germination, sprout growth, sprout quality, and microbial load of two adzuki bean (Vigna angularis) varieties (Kaohsiung 8 and Kaohsiung 10). The results indicated that the ultrasonication at $40 \mathrm{kHz}$ or $80 \mathrm{kHz}$ improved seed hydration and enhanced germination; this is linked to the ultrasound-induced microstructure changes in the hilum and seed coat surface of treated seeds. The ultrasonication-increased sprout growth and yield were possibly attributable to the increased $\alpha$-amylase activity during germination. Ultrasonication also improved total polyphenols, total flavonoids, and total saponins contents and further enhanced the anti-oxidative activities (FRAP and DPPH) of produce sprouts. The results further indicated that the $40 \mathrm{kHz}$ or $80 \mathrm{kHz}$ treatment decreased microbial loads of treated sprouts to an acceptable level; therefore, these two treatments can be used for germination improvement and an effective microbial control treatment for adzuki bean sprout production.
\end{abstract}

Keywords: adzuki bean; germination; microbial load; phytochemical; seed hydration; sprout; ultrasonication

\section{Introduction}

Adzuki bean (Vigna angularis), a member of the family fabaceae, has been cultivated for centuries in Asian countries such as China, Japan, Korea, and Taiwan [1]. The seeds of the adzuki bean have a sweet and nutty taste and plays an important role in the human diet owing to their richness in starch and protein in addition to high levels of dietary fiber, minerals, and vitamins [2]. It also contains large amounts of polyphenols, flavonoids, and saponins [1], which are known to have anti-inflammatory and anti-bacterial properties that exhibits many beneficial effects for human health. In Chinese folk medicine, adzuki bean seeds are used to treat diuretic functions and other diseases such as dropsy and beriberi [1].

Soybean (Glycine max), mung bean (Vigna radiata), alfalfa (Medicago sativa), and sprouts are the products obtained from the germination of seeds that are harvested before the development of true leaves and they are intended to be eaten whole. Sprout is a nutritious ready-to-eat vegetable worldwide [3]. Adzuki bean seeds are also consumed as sprouts because of their soft and crispy texture and attractive fragrance. However, the seed coat of the adzuki bean is hard when compared to other legumes [4]. This hard seed coat characteristic is linked to the polyphenols and suberin compounds accumulated in the palisade layer of seed coat, which reduces water permeability [5]. As a result, the germinations of some adzuki bean varieties are relatively low compared to other legumes such as soybean and mung bean [6] and consequently affects their sprouts production. Another concern is that the produced sprouts are vulnerable to microbial contamination, which can result from the microbial load on the harvested seeds and the microbial multiplication during sprouting [7]. Therefore, an effective seed treatment, which can improve seed 
germination and the diminishing of microbial contaminants, is helpful for adzuki bean sprouts production.

Ultrasonication is a technique that involves the application of ultrasound (frequency ranges generally between $20 \mathrm{kHz}$ and $100 \mathrm{kHz}$ ) to interact with the materials by using a liquid medium [8]. It is often used in the food industry for improving physical and chemical reactions of treated materials in various applications $[9,10]$. Ultrasonication is also known to stimulate germination in many legumes such as mung bean [11], pea (Pisum sativum) [12], chickpea (Cicer arietinum) [13], and soybean [14]. The ultrasonically increased germination is caused by the mechanical effects of ultrasonic acoustic cavitation. The oscillation and collapse of cavitation bubbles driven by ultrasonic frequencies would impose a mechanical pressure on the cell wall of treated seeds and increases the porosity of cell wall, which subsequently improves water uptake. The improved water uptake in germinating seeds would result in a germination improvement $[15,16]$. Ultrasonication is also reported to improve sprout production and reduce microbial load in pea sprouts [12]. Ultrasonication treatment is also able to reduce the level of microbial load on alfalfa and broccoli seeds but the germination of treated seeds is decreased to some extent [17]. Thus, the efficacy of ultrasonication on seed decontamination appears to be species-dependent.

Ultrasonication treatments have been reported to improve germination in different varieties of bean seeds. However, there are limited reports about its effect on adzuki bean seed germination $\left(40 \mathrm{kHz}\right.$ of ultrasound treatment for $1 \mathrm{~min}$ at $\left.25^{\circ} \mathrm{C}\right)$ [7]. This research aimed to find the best ultrasonication frequency to produce enhanced germination response for the tested two adzuki bean varieties. Special attention was given to the contents of several phytochemicals including total polyphenols, total flavonoids, total saponins, and the antioxidant activities in the ultrasonication treated seeds were also examined. The effects of ultrasonication treatments to reduce microbial contaminations on the produced sprouts were also examined.

\section{Materials and Methods}

\subsection{Seed Materials}

Two commercially produced adzuki bean (Vignaan gularis) varieties Kaohsiung 8 (KH 8, 100 seeds, and $16.8 \mathrm{~g}$ in weight) and Kaohsiung 10 (KH 10, 100 seeds, and $15.4 \mathrm{~g}$ in weight) were used in all the experiments. The seeds with about $19 \%$ seed moisture content on dry weight basis were stored at $4{ }^{\circ} \mathrm{C}$ before they were used for testing.

\subsection{Ultrasonication Treatment}

The ultrasonication treatments were conducted by soaking $100 \mathrm{~g}$ of seeds in $2 \mathrm{~L}$ of deionized water in an ultrasonic bath with a power of $300 \mathrm{~W}$ (RingTech, MU 301$30 \mathrm{~L}$, Taichung, Taiwan) [12]. The applied frequencies were $28 \mathrm{kHz}, 40 \mathrm{kHz}$, or $80 \mathrm{kHz}$, respectively, for $10 \mathrm{~min}$ at $25^{\circ} \mathrm{C}$. A subsample of non-treated control was prepared by soaking the seeds in deionized water for $10 \mathrm{~min}$ at $25^{\circ} \mathrm{C}$.

\subsection{Seed Hydration and Germination Determinations}

Fifty seeds sampled from each ultrasonication treatment were germinated in a growth chamber (ES4-1S, Saint Tien Co. Ltd., Kaoshiung city, Taiwan) in the dark at $20{ }^{\circ} \mathrm{C}$ for 6 days. The germination percentage and mean germination time (MGT) were calculated following the procedures detailed by Chiu and Sung [12]. For water uptake determination, thirty seeds were weighed to obtain the initial weight and then the weights were measured at the following periods: $1,2,3,4,5$, and 6 days. The moisture uptake was determined as a function of seed fresh weight increase and seed weight difference at each sampling time.

A subsample of the seeds of $10 \mathrm{~g}$ from each treatment was germinated under the similar conditions for 6 days, and the growing sprouts were collected for hypocotyl length, radicle lengths, and sprout fresh weight measurements. 


\section{4. $\alpha$-Amylase Activity Determinations}

For $\alpha$-amylase activity determination, the adzuki bean seeds were ground and sifted through a $0.75 \mathrm{~mm}$ sieve. Approximately $1 \mathrm{~g}$ of ground sample was added to a centrifuge tube containing $5 \mathrm{~mL}$ of $50 \mathrm{mM}$ sodium phosphate buffer ( $\mathrm{pH} 8)$. Extraction was performed for $30 \mathrm{~min}$ at $30{ }^{\circ} \mathrm{C}$ and then the centrifuge tube was centrifuged for $10 \mathrm{~min}$ at $3000 \mathrm{~g}$. The supernatant was used as $\alpha$-amylase extract. Alpha-amylase activity was determined by measuring the reducing sugars produced by its action on soluble starch by using a 3,5-dinitrosalicylic acid method [18].

\subsection{Scanning Electron Microscopy Examinations}

The adzuki bean seed was cut with a razor blade and was attached to stabs using a double-sided adhesive tape. The prepared sample was coated with $30 \mathrm{~nm}$ of gold using a Technics Hummer V sputter coater. The coated sample was scanned and examined using a Hitachi S-3400N microscope operating at $30 \mathrm{kV}$.

\subsection{Phytochemicals and Anti-Oxidative Activities Determinations}

The adzuki bean sprouts were dried and ground and sifted through a $0.75 \mathrm{~mm}$ sieve. Five grams of the ground adzuki bean sample was added to $100 \mathrm{~mL}$ of acidified ethanol $(60 \%$ ethanol with $2 \% \mathrm{HCl}, \mathrm{pH} 1.5)$ and extracted following the procedures detailed by Zhao et al. [19]. The produced extract was used for phytochemical contents and anti-oxidative activities determinations. Total polyphenols were determined using the Folin-Ciocalteu reagent method [20]. The content of total polyphenols was calculated and expressed as milligrams of gallic acid equivalents (GAE) per gram of sprout sample fresh weight. Total flavonoids were estimated by using an $\mathrm{AlCl}_{3}$ method [21]. Total flavonoids content was calculated and expressed as milligrams of catechin equivalents per gram of sprout sample fresh weight. Total saponins determination was conducted using an anisaldehyde method [22]. The content of saponins was calculated and expressed as $\mathrm{mg} \mathrm{g}^{-1}$ bean sprout sample fresh weight.

Free radical scavenging ability of the bean sprout sample extract was carried out tested by 2,2-diphenyl-1-picrylhydrazyl (DPPH) radical scavenging assay method [22]. The results were expressed as percentage inhibition at $100 \mu \mathrm{g} \mathrm{mL}^{-1}$. The Ferric Reducing Antioxidant Power (FRAP) ability of the sprout sample was determined using the method of Benzie and Strain [23]. The results were expressed as $\mu \mathrm{mol}$ trolox equivalent per $\mathrm{g}^{-1}$ sprout sample FW.

\subsection{Data Analysis}

A complete randomized block design with three replicates was used to evaluate the effects of ultrasonication treatments on the two tested adzuki bean seeds. The data were presented by using mean \pm standard deviation (SD) and statistical significances were determined according to Fisher's least significant difference (LSD) test.

\section{Results and Discussion}

\subsection{Ultrasonication Treatment on Seed Hydration}

The hydration process in seeds is the first step toward germination. This process is essential to change the status of seed development from a state of quiescence to active growth. The rate of water uptake is initially controlled by the seed coat. Bewley et al. [24] reported that depending on the seed coat permeability, seeds can hydrate following two different behaviors: downward concave shape and sigmoidal shape. In this study, both varieties Kaohsiung 8 (KH 8) and Kaohsiung 10 (KH 10) exhibited sigmoidal behavior on seed hydration (Figure 1), which was characterized by rapid water uptake at the early phase followed by slow water uptake and finally a much faster rate of water uptake. Significant hydration difference existed between the non-treated control seeds of two varieties; the KH 8 seed exhibited faster and higher water uptake than the KH 10 seed. This difference in hydration process might be linked to the different testa microstructures observed between 
the two tested varieties. As is shown in Figure 2, only one macrosclereids layer was found in the seed coat of $\mathrm{KH} \mathrm{8,} \mathrm{while} \mathrm{the} \mathrm{seed} \mathrm{coat} \mathrm{of} \mathrm{KH} 10$ had two macrosclereids layers. The two macrosclereids layer microstructure may affect the entrance of water and subsequently slow down the hydration of the KH 10 seed [24].

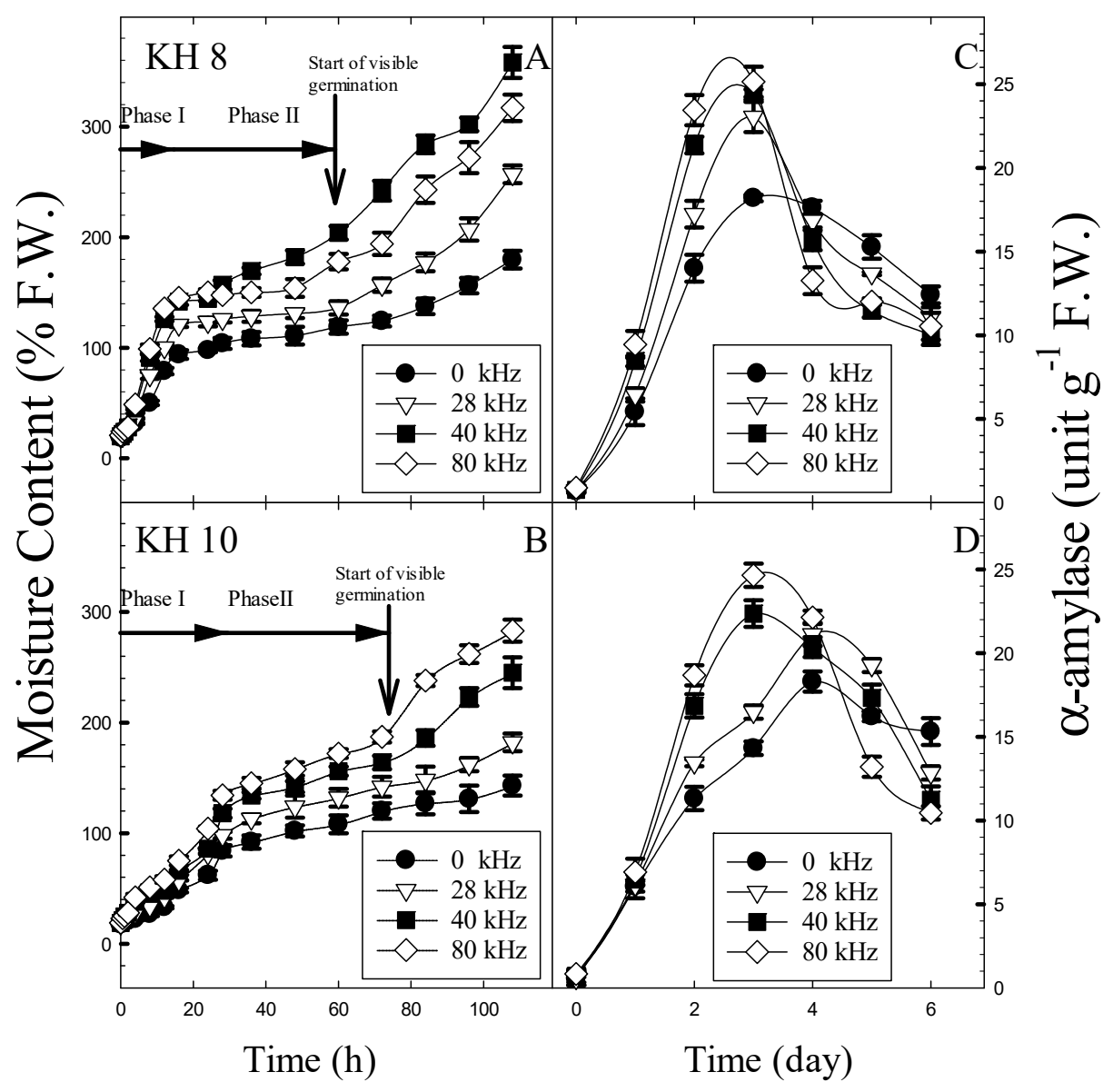

Figure 1. Water absorption and $\alpha$-amylase activity characteristics of two adzuki bean varieties. Kaohsiung 8 (KH 8) and Kaohsiung 10 (KH 10) seeds were subjected to different ultrasonication treatments $\left(28 \mathrm{kHz}, 40 \mathrm{kHz}\right.$ and $80 \mathrm{kHz}$ frequencies for $10 \mathrm{~min}$ under $25^{\circ} \mathrm{C}$ ) during different germination periods.

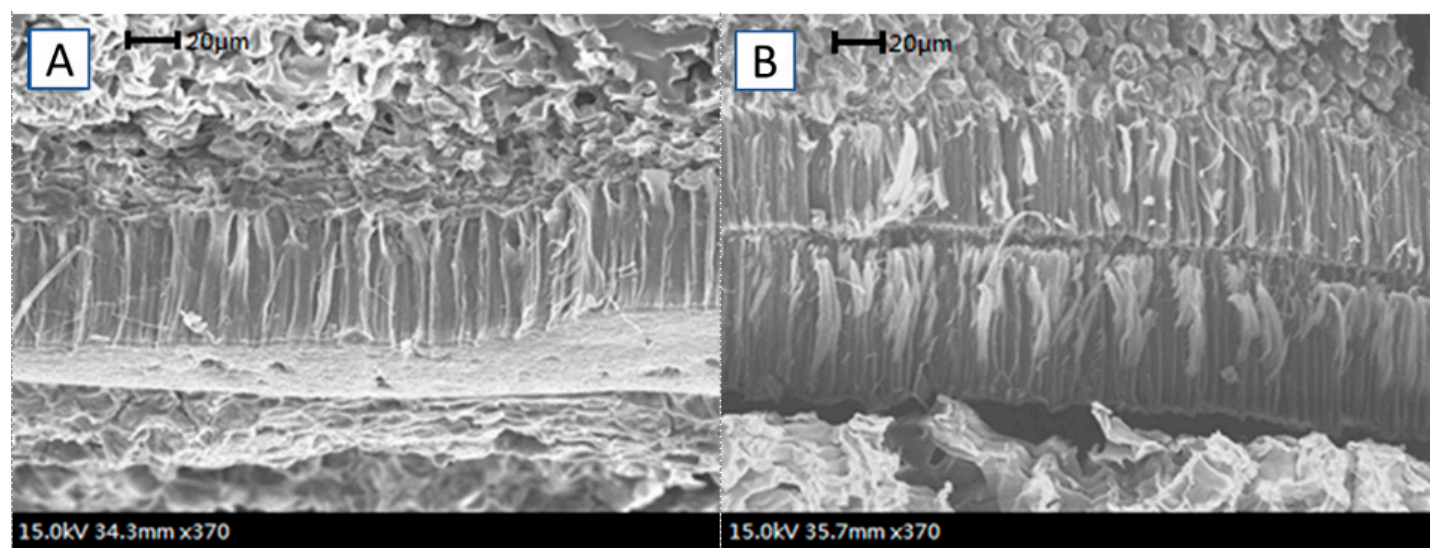

Figure 2. The microstructure of macroesclereids layers of adzuki bean seeds of two varieties: (A) Kaohsiung 8 and (B) Kaohsiung 10 grain microstructure (SEM, 15 kV, 370 X). 
Hilum is known to be the main water intake route during legume seed hydration. As is shown in Figure 3A, the hilum of the tested adzuki bean seed had some visible intercellular spaces which were porous. These porous spaces were involved in the exchange of gases and water between the seed and the external environment [15]. Moreover, the seed coat surfaces of non-treated adzuki bean seeds were almost not porous (Figure 3C) in contrast to the hila which were relatively porous (Figure 3A).
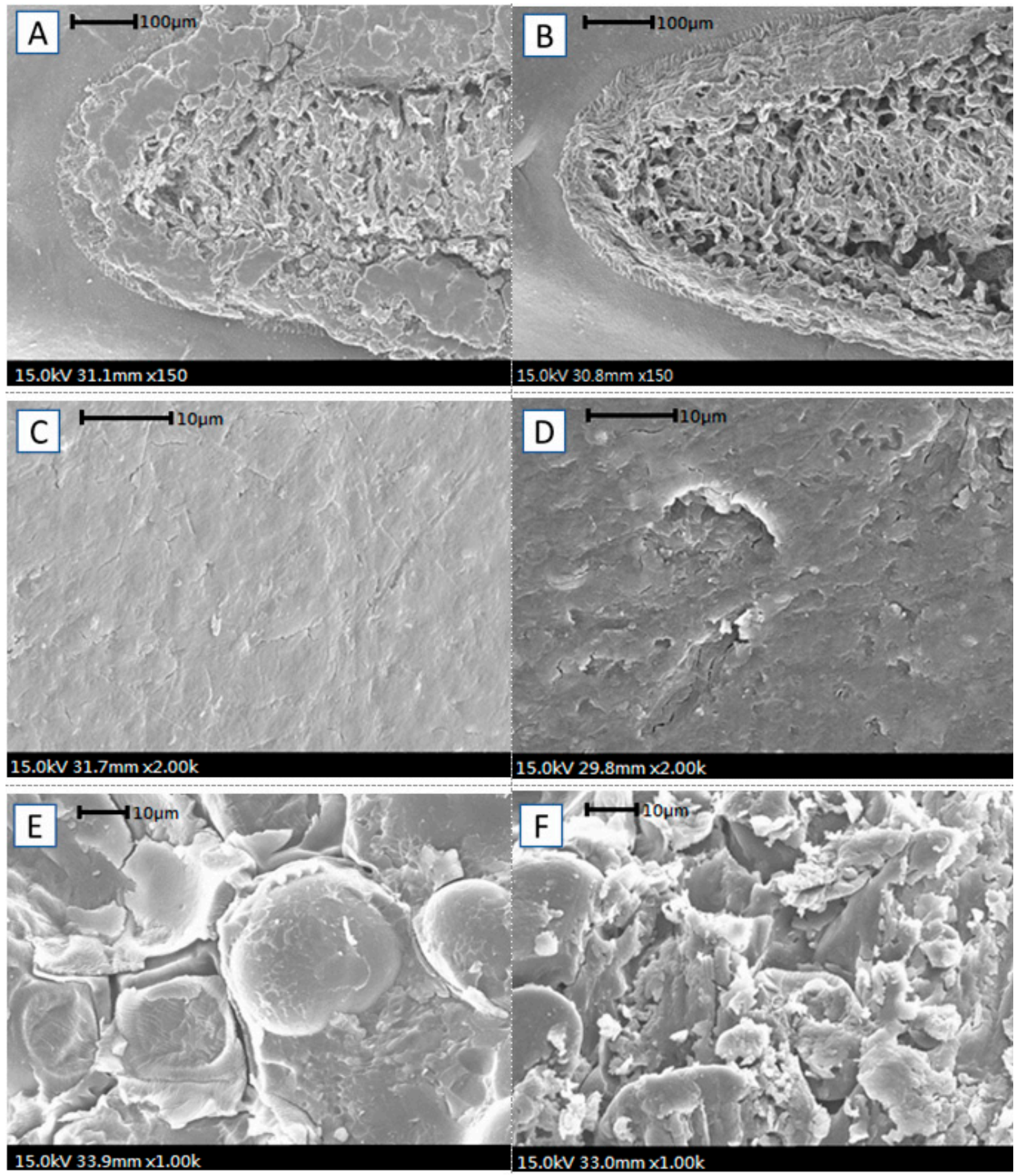

Figure 3. The microstructure of the hila, seed coat surfaces, and starch granules of adzuki bean seeds of two varieties: (A) hilum of Kaohsiung 8, non-treated control seed (1.5 kV, $150 \mathrm{X})$; (B) hilum of Kaohsiung 8, $80 \mathrm{kHz}$ ultrasonication treated seed $(1.5 \mathrm{kV}, 150 \mathrm{X})$; (C) seed coat surface of Kaohsiung 8, non-treated seed $(1.5 \mathrm{kV}, 2.0 \mathrm{kX})$; (D) seed coat surface of Kaohsiunh 8, $80 \mathrm{kHz}$ ultrasonication treated seed $(1.5 \mathrm{kV}, 2.0 \mathrm{kX})$; (E) starch granules of Kaohsiung 8, non-treated control seed $(1.5 \mathrm{kV}, 1.0 \mathrm{kX})$; (F) starch granules of Kaohsiung 8, $80 \mathrm{kHz}$ ultrasonication treated seed $(1.5 \mathrm{kV}, 1.0 \mathrm{kX})$. 
Ultrasound is defined as sound waves possessing a frequency that exceeds the hearing limit of the human ear $(\sim 20 \mathrm{kHz})$ [25]. The application of ultrasonication has demonstrated positive results in accelerating the hydration of mung bean seed [15]. As was shown in Figure 1, the water absorption of adzuki bean seeds that were subjected to ultrasonication treatment $(28-80 \mathrm{kHz})$ increased substantially during seed hydration. The highest water absorption for $\mathrm{KH} 8$ was obtained from the seeds subjected to $40 \mathrm{kHz}$ frequency ultrasonication treatment and were followed by $80 \mathrm{kHz}$ and $28 \mathrm{kHz}$ treatments at the end of $50 \mathrm{~h}$ of seed hydration (Figure 1A). On the other hand, the water uptake of KH 10 followed the descending order of $80 \mathrm{kHz}>40 \mathrm{kHz}>28 \mathrm{kHz}$ (Figure 1B). The increased water absorptions observed in the treated seeds were believed to be linked to the ultrasonication-induced microstructure changes observed on the hila and seed coat surfaces (Figure 3). The hilum of adzuki bean seeds subjected to $40 \mathrm{kHz}$ (Figures are not shown) and $80 \mathrm{kHz}$ ultrasonication had considerably more intercellular space than their respective controls (Figure 3B). Moreover, the seed coat surface of $80 \mathrm{kHz}$ treated seeds appeared to have some visible cracks (Figure 3D) in contrast to the seed coat of the control seeds (Figure 3C).

\subsection{Ultrasonication Treatment on Seed Germination and $\alpha$-Amylase Activity}

Non-treated control seeds of varieties $\mathrm{KH} 8$ and $\mathrm{KH} 10$ had $66.1 \%$ and 34.5\% of germination percentage and 4.43 days and 5.65 days of mean germination time (MGT), respectively (Table 1 ). The germination percentage of variety $\mathrm{KH} 10$ was considerably lower than $\mathrm{KH} \mathrm{8;} \mathrm{this} \mathrm{is} \mathrm{possibly} \mathrm{caused} \mathrm{by} \mathrm{its} \mathrm{slower} \mathrm{water} \mathrm{absorption} \mathrm{and} \mathrm{the} \mathrm{different}$ testa microstructure (Figures 1 and 2). All the ultrasonication treated seeds of KH 8 and $\mathrm{KH} 10$ showed improved germination percentage and accelerated germination speed in comparison to their respective controls (Table 1). However, $80 \mathrm{kHz}$ treated seeds performed better than the $28 \mathrm{kHz}$ and $40 \mathrm{kHz}$ treated seeds (Table 1). The best MGT was 2.43 days and 2.78 days for $\mathrm{KH} 8$ and $\mathrm{KH} \mathrm{10,} \mathrm{respectively} \mathrm{(40} \mathrm{kHz} \mathrm{treated} \mathrm{seed)} \mathrm{(Table} \mathrm{1).}$

Table 1. Effects of different ultrasonication treatments $(28 \mathrm{kHz}, 40 \mathrm{kHz}$ and $80 \mathrm{kHz})$ on the germination percentage, mean germination time, hypocotyl length, radicle length, and sprout yield of 6-days-old sprouts of two adzuki bean varieties.

\begin{tabular}{|c|c|c|c|c|c|c|}
\hline & $\begin{array}{c}\text { Ultrasonication } \\
\text { Treatment }\end{array}$ & Germination & $\begin{array}{c}\text { Mean } \\
\text { Germination Time }\end{array}$ & $\begin{array}{l}\text { Hypocotyl } \\
\text { Length }\end{array}$ & Radicle Length & $\begin{array}{l}\text { Sprout Fresh } \\
\text { Weight }\end{array}$ \\
\hline Variety & $(\mathrm{kHz})$ & $(\%)$ & (days) & $(\mathrm{cm})$ & $(\mathrm{cm})$ & (g $10 \mathrm{~g}^{-1}$ seeds) \\
\hline \multirow{4}{*}{ KH8 } & 0 & $66.1 \pm 4.1$ & $4.43 \pm 0.1$ & $5.43 \pm 0.0$ & $6.72 \pm 0.1$ & $212.4 \pm 4.4$ \\
\hline & 28 & $87.2 \pm 2.3$ & $3.48 \pm 0.2$ & $5.92 \pm 0.0$ & $7.62 \pm 0.0$ & $238.6 \pm 9.8$ \\
\hline & 40 & $97.2 \pm 2.4$ & $2.43 \pm 0.1$ & $7.25 \pm 0.0$ & $8.46 \pm 0.1$ & $331.5 \pm 6.8$ \\
\hline & 80 & $92.3 \pm 2.2$ & $2.63 \pm 0.2$ & $6.73 \pm 0.1$ & $7.64 \pm 0.1$ & $283.4 \pm 5.8$ \\
\hline \multirow{5}{*}{ KH10 } & 0 & $34.5 \pm 3.4$ & $5.65 \pm 0.7$ & $2.42 \pm 0.0$ & $1.24 \pm 0.0$ & $167.6 \pm 3.4$ \\
\hline & 28 & $78.5 \pm 2.2$ & $4.63 \pm 0.2$ & $3.84 \pm 0.0$ & $2.83 \pm 0.0$ & $211.4 \pm 4.3$ \\
\hline & 40 & $94.9 \pm 1.5$ & $3.12 \pm 0.1$ & $5.56 \pm 0.0$ & $6.25 \pm 0.0$ & $253.9 \pm 5.2$ \\
\hline & 80 & $94.6 \pm 1.6$ & $2.78 \pm 0.1$ & $6.84 \pm 0.1$ & $7.47 \pm 0.1$ & $274.8 \pm 6.7$ \\
\hline & $\mathrm{LSD}_{0.05}$ & 3.16 & 0.14 & 0.30 & 0.10 & 13.13 \\
\hline
\end{tabular}

Chen et al. [26] reported that the germination percentage and the germination speed were possibly enhanced because ultrasound vibration caused changes in the cellular ultrastructure that could improve the release of enzymes from the cell wall and biochemical metabolism. Alpha-amylase is an enzyme found in the germinating seeds. The imbibition process causes the release of plant growth hormones (i.e., gibberellin) which stimulates the synthesis of amylase. In this study, we examined the activities of $\alpha$-amylase in control and ultrasonication-treated adzuki seeds and the results were shown in Figure 1. During the different germination period, the maximum $\alpha$-amylase activity was found at three days in $\mathrm{KH} 8$ variety (18 unit/g FW), while the maximum $\alpha$-amylase activity of KH 10 was found at four days. 
Ultrasonication was shown to affect the water absorption pattern of treated adzuki bean seeds. Therefore, it was not surprising to find that the $\alpha$-amylase activities were changed during seed hydration. As was shown in Figure 1, the $\alpha$-amylase activities of the treated seeds of adzuki bean varieties were higher than that of the control seeds in the earlier germination phases. The maximum activities of $80 \mathrm{kHz}$ treated seeds were increased by $53 \%$ and $39 \%$ for KH 8 and KH 10 compared to their respective controls. The maximum activities of $28 \mathrm{kHz}$ treated seeds were also increased by $29 \%$ and $24 \%$ for $\mathrm{KH} 8$ and $\mathrm{KH} 10$ compared to their respective controls. The ultrasonication-stimulated $\alpha$-amylase activities during the early phase of seed hydration were possibly caused by the ultrasound-induced starch granule damages (Figure 3F). The starch granules of non-treated adzuki seeds were characterized by a compact and homogeneous structure embedded in a matrix. However, this smooth starch granule structure was partially damaged by $80 \mathrm{kHz}$ ultrasonication treatment (Figures for $28 \mathrm{kHz}$ and $40 \mathrm{kHz}$ treatments are not shown), especially for the KH 8 seed. The damaged starch granules would favor the starch hydrolysis through hydration-activated $\alpha$-amylase activity and then enhance seed germination.

\subsection{Effects of Ultrasonication Treatments on Sprouts Growths and Yields}

Significant differences in sprout growth existed between the two tested varieties (Table 1). The sprouts of variety $\mathrm{KH} 8$ exhibited longer hypocotyl and radicle lengths than the sprouts of variety $\mathrm{KH} 10$. Variety KH 8 was also out yielded in sprouts than variety $\mathrm{KH} 10$. The yields of sprouts produced from non-treated $\mathrm{KH} 8$ and $\mathrm{KH} 10$ were $212.4 \mathrm{~g}$ and $167.6 \mathrm{~g}$ per $10 \mathrm{~g}$ seeds, respectively.

Significant differences in hypocotyls and radicle lengths also existed among ultrasonication treatments. All the ultrasonication treatments increased hypocotyl and radicle growths. Among the treatments, $\mathrm{KH} 8$ and $\mathrm{KH} 10$ sprouts produced from $40 \mathrm{kHz}$ and $80 \mathrm{kHz}$ ultrasonication-treated seeds exhibited the highest sprout growth improvements (Table 1). Significant differences in sprout yield were also found among ultrasonication treatments. The greatest yield increases were obtained from the $40 \mathrm{kHz}$ ultrasonication treated KH8 (331.5 g $10 \mathrm{~g} \mathrm{~g}^{-1}$ seeds) and $80 \mathrm{kHz}$ ultrasonication treated $\mathrm{KH} 10$ (274.8 g $10 \mathrm{~g}^{-1}$ seeds) seeds.

\subsection{Ultrasonication Treatment on Sprout Phytochemicals}

Polyphenols and flavonoids are commonly known as the phytochemical molecules with antioxidative properties from plants [27]. Results of total polyphenols, total flavonoid, and total saponins content in the tested adzuki bean sprouts are shown in Table 2. The non-treated sprouts (control) of KH 8 contained more total polyphenols and total saponins but less total flavonoids than the non-treated sprouts of KH 10. The levels of total polyphenols found in our study were substantially higher than that of the levels reported by Świeca et al. [28]. They reported that the level of total polyphenols in the tested 5-days-old adzuki bean sprouts was around $0.11 \mathrm{mg}$ per gram dry weight. However, in the present study, the levels of total polyphenols in the tested sprouts were around $4.05 \mathrm{mg} / \mathrm{g}$ DW (average of two varieties) (Table 2). The total flavonoid content of tested adzuki bean sprouts $(1.31 \mathrm{mg} / \mathrm{g}$ DW, average of two varieties) was also considerably higher than the total flavonoid content of black bean $(0.22 \mathrm{mg} / \mathrm{g}$ DW) reported by Borges-Martínez et al. [29].

Saponins are reported to have a plasma cholesterol lowering effect in humans and are important in reducing the risk of many chronic diseases [30]. In this study, total saponins were detectable in both KH 8 (12.43 mg per g DW) and KH 10 (10.33 mg per g DW) sprouts (Table 2) and these total saponins values were higher than the saponins level $(2.06 \mathrm{mg} / \mathrm{g})$ found in black bean sprout [31]. 
Table 2. Effects of different ultrasonication treatments $(28 \mathrm{kHz}, 40 \mathrm{kHz}$ and $80 \mathrm{kHz})$ on the total polyphenols, total flavonoids, total saponins, and antioxidative abilities (FRAP and DPPH) of 6-days-old sprouts of two adzuki bean varieties.

\begin{tabular}{|c|c|c|c|c|c|c|c|}
\hline & $\begin{array}{l}\text { Ultrasonication } \\
\text { Treatment }\end{array}$ & $\begin{array}{c}\text { Total } \\
\text { Polyphenols }\end{array}$ & $\begin{array}{c}\text { Total } \\
\text { Flavonoids }\end{array}$ & $\begin{array}{c}\text { Total } \\
\text { Sapanins }\end{array}$ & FRAP & DPPH & $\begin{array}{c}\text { Total } \\
\text { Polyphenols }\end{array}$ \\
\hline Variety & $(\mathrm{kHz})$ & $\begin{array}{c}\text { (mg gallic acid } \\
\mathrm{g}^{-1} \text { F.W.) }\end{array}$ & $\begin{array}{c}\text { (mg CAE g } g^{-1} \\
\text { F.W.) }\end{array}$ & $\left(\mathrm{mg} \mathrm{g}^{-1}\right.$ F.W.) & $\begin{array}{l}\text { (mmol Trolox } \\
100 \mathrm{~g}^{-1} \text { F.W.) }\end{array}$ & $\begin{array}{l}\text { (\% inhibition at } \\
100 \mathrm{ug} \mathrm{mL}^{-1} \text { ) }\end{array}$ & $\begin{array}{c}\text { (mg gallic acid } \\
\mathrm{g}^{-1} \text { F.W.) }\end{array}$ \\
\hline \multirow{4}{*}{ KH8 } & 0 & $4.34 \pm 0.04$ & $1.13 \pm 0.01$ & $12.43 \pm 0.10$ & $8.22 \pm 0.07$ & $60.01 \pm 1.2$ & $4.34 \pm 0.04$ \\
\hline & 28 & $6.62 \pm 0.04$ & $1.65 \pm 0.01$ & $15.10 \pm 0.09$ & $11.53 \pm 0.09$ & $62.38 \pm 2.6$ & $6.62 \pm 0.04$ \\
\hline & 40 & $8.44 \pm 0.06$ & $1.60 \pm 0.01$ & $17.22 \pm 0.11$ & $13.93 \pm 0.10$ & $65.68 \pm 1.2$ & $8.44 \pm 0.06$ \\
\hline & 80 & $5.89 \pm 0.05$ & $1.44 \pm 0.02$ & $15.49 \pm 0.13$ & $12.29 \pm 0.06$ & $61.01 \pm 1.3$ & $5.89 \pm 0.05$ \\
\hline \multirow{5}{*}{ KH10 } & 0 & $3.76 \pm 0.03$ & $1.49 \pm 0.01$ & $10.33 \pm 0.08$ & $7.06 \pm 0.05$ & $58.37 \pm 1.2$ & $3.76 \pm 0.03$ \\
\hline & 28 & $7.04 \pm 0.06$ & $2.64 \pm 0.02$ & $15.53 \pm 0.13$ & $12.46 \pm 0.10$ & $62.66 \pm 1.3$ & $7.04 \pm 0.06$ \\
\hline & 40 & $8.89 \pm 0.06$ & $2.48 \pm 0.02$ & $18.45 \pm 0.12$ & $14.66 \pm 0.09$ & $64.50 \pm 1.1$ & $8.89 \pm 0.06$ \\
\hline & 80 & $8.86 \pm 0.07$ & $2.04 \pm 0.03$ & $19.40 \pm 0.16$ & $15.70 \pm 0.13$ & $68.79 \pm 1.7$ & $8.86 \pm 0.07$ \\
\hline & $\mathrm{LSD}_{0.05}$ & 0.28 & 0.13 & 1.01 & 0.41 & 3.45 & 0.28 \\
\hline
\end{tabular}

Ultrasonication treatment also affected the levels of total polyphenols, the total flavonoids contents and saponin in the sprouts of both adzuki bean varieties (Table 2). The highest levels of total polyphenols were found on the $40 \mathrm{kHz}$ treated adzuki bean sprouts followed by $80 \mathrm{kHz}$ and $28 \mathrm{kHz}$ treated adzuki bean sprouts (Table 2). On the other hand, the highest levels of total flavonoids were found on the $28 \mathrm{kHz}$ treated sprouts followed by $40 \mathrm{kHz}$ and $80 \mathrm{kHz}$ treated sprouts (Table 2). The contents of saponins for ultrasonication-treated KH8 sprouts were decreased in a descending order of $40 \mathrm{kHz}>80 \mathrm{kHz}>28 \mathrm{kHz}$, while the contents of saponins for ultrasonication-treated $\mathrm{KH} 10$ sprouts were decreased in a descending order of $80 \mathrm{kHz}>40 \mathrm{kHz}>28 \mathrm{kHz}$.

\subsection{Ultrasonication Treatment on Antioxidative Potentials}

In this study two in vitro assays, ferric reducing antioxidant potential (FRAP) assay and DPPH radical scavenging capacity assay, were used to evaluate the antioxidant activities of two adzuki bean seeds (Table 2). The results of the FRAP assay showed that the sprout of variety KH 10 showed higher FRAP antioxidant activity $(2.51 \mu \mathrm{mol}$ Trolox per $100 \mathrm{~g}$ DW) than the sprout of KH 8 (2.14 $\mu$ mol Trolox per $100 \mathrm{~g}$ DW). The FRAP of KH 8 and $\mathrm{KH} 10$ sprouts were found lower than the adzuki bean sprout study of Bai et al. [32] $(15.27 \mu \mathrm{mol}$ Trolox per $100 \mathrm{~g})$. The results of the DPPH assay showed that the sprout of variety $\mathrm{KH} 10$ showed higher DPPH activity (88.6\% inhibition at $100 \mu \mathrm{g} / \mathrm{mL})$ than the sprout of KH $8(82.4 \%$ inhibition at $100 \mu \mathrm{g} / \mathrm{mL})$. The DPPH activities of $\mathrm{KH} 8$ and $\mathrm{KH}$ 10 sprouts were found substantially higher than the soybean sprout study of Soedarjo et al. [33] (about 29\% inhibition at $100 \mu \mathrm{g} / \mathrm{mL}$ ). The results of the DPPH assay showed that the sprouts of variety KH 10 showed higher DPPH activity $(88.6 \%$ inhibition at $100 \mu \mathrm{g} / \mathrm{mL})$ than the sprouts of KH $8(82.4 \%$ inhibition at $100 \mu \mathrm{g} / \mathrm{mL})$.

A large variation in FRAP and DPPH ranging from 1.92 to $2.42 \mathrm{mg}^{\text {trolox }} \mathrm{g}^{-1} \mathrm{~g}$ dry weight and from $83.2 \%$ to $88.2 \%$, respectively, was also observed for the ultrasonicationtreated adzuki bean sprouts (Table 2). In general, the sprouts subjected to ultrasonication treatment tended to have relatively lower FRAP and DPPH activities as comparing to the control sprouts (Table 2). These results were different from the FRAP and DPPH activities of mung bean sprouts reported by Singh et al. [34].

\subsection{Effects of Ultrasonication Treatments on Microbial Loads}

The sprouts produced from control sprouts of KH 8 and KH 10 exhibited total aerobic bacterial counts of 9.22 and $11.81 \log _{10} \mathrm{CFU} \mathrm{g}{ }^{-1}$ fresh weights, respectively (Table 3). They further exhibited total coliform counts of 6.29 and $7.35 \log _{10} \mathrm{CFU} \mathrm{g} \mathrm{g}^{-1}$ fresh weight and total mould counts of 7.46 and $8.12 \log _{10} \mathrm{CFU} \mathrm{g}{ }^{-1}$ fresh weight, respectively (Table 3). These values were considerably higher than the microbial load in adzuki sprouts $(11.81,7.35$ and $8.12 \log _{10} \mathrm{CFU} \mathrm{g}{ }^{-1}$ fresh weight for total aerobic, total coliform, and total mould counts, respectively) previously reported by Chiu [7]. The increased microbial populations on the 
produced adzuki bean sprouts can be attributable to the microbes present on the seeds and the favorable environmental conditions (e.g., soaking water and sprouting temperature) in which they are grown [35].

Table 3. Effects of different ultrasonication treatments $(28 \mathrm{kHz}, 40 \mathrm{kHz}$ and $80 \mathrm{kHz})$ on the microbial loads of 6-days-old sprouts of two adzuki bean varieties.

\begin{tabular}{ccccc}
\hline & $\begin{array}{c}\text { Ultrasonication } \\
\text { Treatment }\end{array}$ & $\begin{array}{c}\text { Total Aerobic } \\
\text { Bacterial Count }\end{array}$ & $\begin{array}{c}\text { Total Coliforms } \\
\text { Count }\end{array}$ & $\begin{array}{c}\text { Total Mould } \\
\text { Count }\end{array}$ \\
\hline Variety & $(\mathrm{kHz})$ & \multicolumn{2}{c}{$\left(\log _{10}\right.$ CFU g ${ }^{-1}$ fresh weight $)$} \\
\hline \multirow{3}{*}{ KH8 } & 0 & $9.22 \pm 1.74$ & $6.29 \pm 0.87$ & $7.46 \pm 0.43$ \\
& 28 & $4.78 \pm 0.63$ & $2.38 \pm 0.14$ & $3.61 \pm 0.23$ \\
& 40 & $3.79 \pm 0.18$ & $1.48 \pm 0.08$ & $2.76 \pm 0.03$ \\
KH10 & 80 & $3.28 \pm 0.07$ & $0.10 \pm 0.14$ & $2.15 \pm 0.11$ \\
& 0 & $11.81 \pm 1.83$ & $7.35 \pm 0.48$ & $8.12 \pm 0.46$ \\
& 28 & $5.88 \pm 0.74$ & $3.69 \pm 0.09$ & $4.91 \pm 0.34$ \\
& 40 & $4.13 \pm 0.23$ & $2.59 \pm 0.24$ & $2.69 \pm 0.13$ \\
& 80 & $3.93 \pm 0.17$ & $2.37 \pm 0.33$ & $2.33 \pm 0.24$ \\
\hline
\end{tabular}

There are many physical, chemical, and biological methods available to decrease the microbial load of produced sprout [36]. Ultrasonication treatments have been reported to improve germination in different varieties of bean seeds. However, there was only limited report about its effect on adzuki bean seed germination $(40 \mathrm{kHz}$ of ultrasound treatment for $1 \mathrm{~min}$ at $25^{\circ} \mathrm{C}$ ) [7]. In this study, the efficacies of three ultrasonication treatments were compared. The de-contamination efficacy on produced sprouts for total aerobic, total coliforms, and total mould controls were significantly different among the tested ultrasonication treatments, with the descending order of $80 \mathrm{kHz}>40 \mathrm{kHz}>28 \mathrm{kHz}$ (Table 3). To reiterate, significant differences existed between two varieties, with ultrasonication treated $\mathrm{KH} 8$ sprouts generally having less microbial loads than KH 10 sprouts (Table 3).

\section{Conclusions}

This study provides information on seed germination, sprout yield, phytochemicals contents, antioxidative ability, and microbial status of two adzuki bean varieties. The results indicated that all the ultrasonication treatments were able to increase seed hydration, improve germinations, and increase $\alpha$-amylase activities of two tested adzuki bean varieties and subsequently increase their sprout productions. The ultrasonication-improved seed hydration was linked to the ultrasound-induced microstructural changes on the hilum and the surface of seed coats in the treated adzuki bean seeds. Moreover, all the ultrasonication increased the contents of polyphenols, total flavonoids, and total saponins in the treated bean sprouts. Additionally, both FRAP and DPPH activities were enhanced in the ultrasonication-treated sprouts. As for food safety concerns, $80 \mathrm{kHz}$ and $40 \mathrm{kHz}$ ultrasonication treatments were capable of decreasing total aerobic counts of sprouts by 6.5 and $6.3 \mathrm{log}$ unit (averages of two varieties), respectively, while the $28 \mathrm{kHz}$ ultrasonication treatments were unable to decrease total aerobic counts adequately enough ( $\geq 5 \log$ unit) to protect microbial safety for variety $\mathrm{KH} 8$. Moreover, both $40 \mathrm{kHz}$ and $80 \mathrm{kHz}$ ultrasonication were capable of reducing the total coliforms and total mould counts to $<3 \log _{10}$ CFU g ${ }^{-1}$ fresh weights on tested adzuki bean sprouts. Therefore, both the $40 \mathrm{kHz}$ and $80 \mathrm{kHz}$ ultrasonications are an appropriate choice as an effective pretreatment for adzuki bean sprout production. However, the $40 \mathrm{kHz}$ treated $\mathrm{KH} 8$ seeds produced highest sprout yield while the $80 \mathrm{kHz}$ treated KH 10 seeds produced highest sprout yield. Thus, the efficacy of ultrasonication frequency on adzuki bean sprout production appears to be variety-dependent. 
Author Contributions: K.-Y.C. designed, carried out all the experiment, analyzed the data and wrote the manuscript. The author have read and agreed to the published version of the manuscript.

Funding: This research received no external funding.

Institutional Review Board Statement: Not applicable.

Informed Consent Statement: Not applicable.

Data Availability Statement: The data presented in this study are available on request from the corresponding author.

Conflicts of Interest: The author declares no conflict of interest.

\section{References}

1. Liu, R.; Cai, Z.; Xu, B. Characterization and quantifcation of favonoids and saponins in adzuki bean (Vigna angularis L.) by HPLC-DAD-ESI-MSN analysis. Chem. Cent. J. 2017, 11, 93-110. [CrossRef]

2. Adav, U.; Singh, N.; Kaur, A.; Thakur, S. Physico-chemical, hydration, cooking, textural and pasting properties of different adzuki bean (Vigna angularis) accessions. J. Food Sci. Technol. 2018, 55, 802-810. [CrossRef]

3. Swieca, M.; Gawlik-Dzikia, U.; Jakubczyka, A.; Bochnaka, J.; Sikoraa, M.; Suliburskab, J. Nutritional quality of fresh and stored legumes sprouts-effect of Lactobacillus plantarum 299v enrichment. Food Chem. 2019, 288, 325-332. [CrossRef]

4. Kramer, C.; Soltani1, N.; Swanton, C.J.; Robinson, D.E.; Sikkema, P.H. Control of volunteer adzuki bean (Vigna angularis) with preand postemergence herbicides in corn (Zea mays). Can. J. Plant Sci. 2010, 90, 925-932. [CrossRef]

5. Smýkal, P.; Vernoud, V.; Blair, M.W.; Soukup, A.; Thompson, R.D. The role of the testa during development and in establishment of dormancy of the legume seed. Front. Plant Sci. 2014, 5, 351. [CrossRef]

6. Isemura, T.; Kaga, A.; Konishi, S.; Ando, T.; Tomooka, N.; Han, O.K.; Vaughan, D.A. Genome dissection of traits related to domestication in azuki bean (Vigna angularis) and comparison with other warm-season legumes. Ann. Bot. 2007, 100, 1053-1071. [CrossRef]

7. Chiu, K.Y. Ultrasonication-enhanced microbial safety of sprouts produced from selected crop species. J. Appl. Bot. Food Qual. 2015, 88, 120-126. [CrossRef]

8. Yusaf, T.; Al-Juboori, R.A. Alternative methods of microorganism disruption for agricultural applications. Appl. Energy 2014, 114, 909-923. [CrossRef]

9. Ravikumar, M.; Suthar, H.; Desai, C.; Gowda, S.A.J. Ultrasonication: An advanced technology for food preservation. Int. J. Pure Appl. Biosci. 2017, 5, 363-371. [CrossRef]

10. Bhargavaa, N.; Mora, R.S.; Kumarb, K.; Sharanagata, V.S. Advances in application of ultrasound in food processing: A review. Ultrason. Sonochem. 2021, 70, 105293. [CrossRef] [PubMed]

11. Kumara, S.; Gautama, S. A combination process to ensure microbiological safety, extend storage lifeand reduce anti-nutritional factors in legume sprouts. Food Biosci. 2019, 27, 18-29. [CrossRef]

12. Chiu, K.Y.; Sung, J.M. Use of ultrasonication to enhance pea seed germination andmicrobial quality of pea sprouts. Int. J. Food Sci. Technol. 2014, 49, 1699-1706. [CrossRef]

13. Hayta, M.; Isçimen, E.M. Optimization of ultrasound-assisted antioxidant compoundsextraction from germinated chickpea using response surface methodology. LWT Food Sci. Technol. 2017, 77, 208-216. [CrossRef]

14. Yang, Y.; Meier, F.; Lo, J.A.; Yuan, W.; Sze, V.L.P.; Chung, H.-J.; Yuk, H.-G. Overview of recent events in the microbiological safety of sprouts and new intervention technologies. Compr. Rev. Food Sci. Saf. 2013, 12, 265-279. [CrossRef]

15. Miano, C.A.; da Costa Pereira, J.; Castanha, N.; da MattaJúnior, M.D.; Augusto, E.D. Enhancing mung bean hydration using the ultrasound technology: Description of mechanisms and impact on its germination and main components. Sci. Rep. 2016, 6, 388996. [CrossRef] [PubMed]

16. Nazari, M.; Eteghadipour, M. Impacts of ultrasonic waves on seeds: A mini-review. Agric Res. Technol. 2017, 6, 1-5. [CrossRef]

17. Kim, H.J.; Feng, H.; Kushad, M.M.; Fan, X. Effects of ultrasound, irradiation, and acidic electrolyzed water on germination of alfalfa and broccoli seeds and Escherichia coli O157:H7. J. Food Sci. 2006, 71, M168-M173. [CrossRef]

18. Osman, A.M. The advantages of using natural substrate-based methods in assessing the roles and synergistic and competitive intractions of barley malt starch-degrading enzymes. J. Inst. Brew. 2002, 108, 204-214. [CrossRef]

19. Zhao, Y.; Du, S.; Wang, H.; Cai, M. In vitro antioxidant activity of extracts from common legumes. Food Chem. 2014, 152, 462-466. [CrossRef] [PubMed]

20. Nguimbou, R.M.; Boudjeko, T.; Njintang, N.Y.; Himeda, M.; Scher, J.; Mbofung, C.M.F. Mucilage chemical profile and antioxidant properties of giant swamp taro tubers. J. Food Sci. Technol. 2014, 51, 3559-3567. [CrossRef]

21. Shen, Y.; Jin, L.; Xiao, P.; Lu, Y.; Bao, J. Total phenolics, flavonoids, antioxidant capacity in rice grain and their relations to grain color, size and weight. J. Cereal Sci. 2009, 49, 106-111. [CrossRef]

22. Vador, N.; Vador, B.; Hole, R. Simple spectrophotometric methods for standardizing aaurvedic formulation. Indian J. Pharm. Sci. 2012, 74, 161-163. [CrossRef] 
23. Bewley, J.D.; Bradford, K.J.; Hilhorst, H.W.M.; Nonogaki, H. Seeds: Physiology of Development, Germination and Dormancy, 3rd ed.; Springer: New York, NY, USA, 2013; pp. 133-181. Available online: https://www.springer.com/gp/book/9781461446927 (accessed on 3 May 2021).

24. Miano, A.C.; Augusto, P.E.D. From the sigmoidal to the downward concave shape behavior during the hydration of grains: Effect of the initial moisture content on adzuki beans (Vigna angularis). Food Bioprod. Process. 2015, 96, 43-51. [CrossRef]

25. Awad, T.S.; Moharram, H.A.; Shaltout, O.E.; Asker, D.; Youssef, M.M. Applications of ultrasound in analysis, processing and quality control of food: A review. Food Res. Int. 2012, 48, 410-427. [CrossRef]

26. Chen, Y.p.; Liu, Q.; Yue, X.Z. Ultrasonic vibration seeds showed improved resistance to cadmium and lead in wheat seedling. Environ. Sci. Pollut. Res. 2013, 20, 4807-4816. [CrossRef] [PubMed]

27. Duangjai, T.; Areeya, T.; Apinan, P.; Aujana, Y. Flavonoids and other phenolic compounds from medicinal plants for pharmaceutical and medical aspects: An overview. Medicines 2018, 5, 93. [CrossRef]

28. Świeca, M.; Herok, A.; Piwowarczyk, K.; Sikora, M.; Ostanek, P.; Gawlik-Dziki, U.; Kapusta, I.; Czyż, J. Potentially bioaccessible phenolics from mung bean and adzuki bean sprouts enriched with probiotic-antioxidant properties and effect on the motility and survival of AGS human gastric carcinoma cells. Molecules 2020, 25, 2963. [CrossRef] [PubMed]

29. Borges-Martínez, E.; Tzayhri Gallardo-Veláazouez, T.; Anaberta Cardadormartínez, A.; Moguel-Concha, D.; Osorio-Revilla, G.; Ruiz-Ruiz, J.C.; Martínez, C.J. Phenolic compounds profile and antioxidant activity of pea (Pisum sativum L.) and black bean (Phaseolus vulgaris L.) sprouts. Food Sci. Technol 2021. [CrossRef]

30. Singh, B.; Pal Singh, J.P.; Singh, N.; Kaur, A. Saponins in pulses and their health promoting activities: A review. Food Chem. 2017, 233, 540-549. [CrossRef] [PubMed]

31. Guajardo-Flores, D.; Garcia-Patino, M.; Serna-Guerrero, D.; Gutierrez-Uribe, J.A.; Serna-Saldivar, S.O. Characterization and quantification of saponins and flavonoids in sprouts, seed coats and cotyledons of germinated black beans. Food Chem. 2012, 134, 1312-1319. [CrossRef]

32. Bai, Y.; Xu, Y.; Wang, B.; Li, S.; Guo, F.; Hua, H.B.; Zhao, Y.; Yu, Z. Comparison of phenolic compounds, antioxidant and antidiabetic activities between selected edible beans and their different growth. J. Funct. Foods 2017, 35, 694-702. [CrossRef]

33. Soedarjo, M.; Suhartina, S.; Nugrahaeni, N.; Wijanarko, A.; Putri, D.A.; Fatmawati, S. The Antioxidant Activities and Phenolic Content of Improved Soybean Seeds Varieties of Different Grain Sizes. IPTEK J. Technol. Sci. 2020, 31, 83-90. [CrossRef]

34. Singh, B.; Singh, N.; Thakur, S.; Kaur1, A. Ultrasound assisted extraction of polyphenols and their distribution in whole mung bean, hull and cotyledon. J. Food Sci. Technol. 2017, 54, 921-932. [CrossRef] [PubMed]

35. Benincasa, P.; Falcinelli, B.; Lutts, S.; Stagnari, F.; Galieni, A. Sprouted grains: A comprehensive review. Nutrients 2019, 11, 421. [CrossRef] [PubMed]

36. Sikin, A.M.; Zoellner, C.; Rizvi, S.S.H. Current intervention strategies for the microbial safety of sprouts. J. Food Prot. 2013, 76, 2099-2123. [CrossRef] 